\title{
International Baccalaureate Programme in Perm Region (Russia) as a Government Initiative: First Results
}

\author{
Marina Sheveleva \\ Associate Professor, National Research University \\ Higher School of Economics, Russia \\ Anastasiia Redkina \\ Reading Lecturer, National Research University \\ Higher School of Economics, Russia
}

Doi:10.5901/mjss.2013.v4n11p527

\begin{abstract}
International Baccalaureate Diploma Program is an academically challenging self-funded high school program which is recognized by the world's leading universities. It was introduced in one of the regions of Russia (Permskii krai) by the local government with the aim to ensure access to high quality education and to improve regional educational system overall. High school students get international IB diploma while this process is largely financed by the regional government. The aim of this paper is to examine how effective this scheme is and to give recommendations for its improvement.In order to answer the research question different major stakeholder groups were surveyed: students, school-leavers, and teachers. Official documents, underlying the implementation of this program, were analyzed. Analysis of the findings was made with the help of institutional approach. The results of this paper represent benefits and shortcomings for each stakeholder group of the project. The recommendations given in the paper deal with the increase of efficiency of this scheme: additional incentives should be created and introduced to increase benefits for the regional part of the contract.
\end{abstract}

Keywords: International Baccalaureate Diploma Program, educational initiative, government funding, risks and benefits

\section{Introduction}

In the latest decade people have become aware of the fact that knowledge is one of the main components of economic and social development. It can play a key role in the development of countries and regions as well as influence their competitiveness. Furthermore, this component is to a great extent defined by the quality and the level of the educational system development on the chosen territory.

The problem of the human resources development that have all necessary competences and are able to meet global challenges of constantly changing competitive environment is traditionally formulated and discussed with reference to the higher educational system (Salmi et al., 2011). The importance of this problem is recognized all over the world, moreover, it is further proved by the growing number of studies in the area of management and economics of higher education. It is clear that the level of human capital in the country or in the region is defined not only by the quality of the higher education but by the school education as well. Basic competences such as ability to collect and analyze information, critical thinking, creative approach to the question posed, foreign-language skills are introduced in the secondary and high school.

During last two decades Russian educational system has been under the process of constant restructuring. The present-day situation on the level of secondary and high school can be described as controversial, requiring further careful analysis and can not be characterized within the framework of this study. At the same time it should be noted that some restructuring processes and their results are questionable. And while some reforms definitely result in the higher quality of education, overall effectiveness of secondary and high school education can be regarded as insufficient (Kuzminov et al., 2011).

Secondary and high school education in Perm Region (a large industrial region in the middle of Russia with the population of about 2,5 million, with about 1 million people living in Perm) is not an exception form the situation described above. The main problems are unevenness of education quality provided in different parts of the region (urban and rural, 
for example), insufficient adaptiveness of educational system, low attractiveness of school-teacher position for university graduates (The long-term program..., 2013). However, the increase in the education quality is defined as a necessary requirement for the development of the regional investment potential and rising in the standards of living.

A number of projects with the aim to improve the situation is described in the public report of the Ministry of Education in Perm region for 2010 - 20111 (Public report..., 2011). Some of these projects can be classified as systemwide measures aimed to raise attractiveness of school teacher profession or, for example, to develop the system for monitoring quality of education as a service. At the same time there is another rifle approach aimed to develop individual educational establishments or to introduce new educational initiatives.

One of the ways to create a more effective secondary and high school national educational system is to rely on the best international experience. The idea is that the introduction of established educational systems and individual methodical approaches can result in the development of highly successful educational centers in the future. The introduction of International Baccalaureate Programme in Perm Region can be classified as the latter type of reforms. Educational initiative with the aim to open International Baccalaureate schools started in 2007.

This project has been carried on for 5 years that is why it is perfectly possible to analyze it, to estimate its successes and downfalls, to suggest ways to improve this project in the future. Our conclusions are based on the combination of two sources of information: firstly, official documents stating aims and objectives of introducing International Baccalaureate Programme in Perm Region and official reports on the way this project was realized, secondly, surveys of the main beneficiary groups in this project. The following groups can be regarded as main beneficiaries of this project: 1) students and their families, 2) teachers, 3) administration of school where this project was realized, 4) administration of Perm region (represented by civil servants and project leaders in Perm). This scheme of analysis implies the comparison of main beneficiaries' opinions on the key aspects of the project (described in its aims), defining its risks and expected benefits. In the next part of this paper we will give overall description of this educational initiative in Perm region, in the third part we will describe main survey results, in the fourth - analyze them and formulate main benefits and risks of the project. At the end of the paper we will give main conclusions and recommendations on the ways to develop this project with the aim to increase its efficiency.

\section{International Baccalaureate Programme in Perm Region: overall description of the educational initiative}

International Baccalaureate (IB) is a high quality international education programme. Founded in 1968, this non-profit organization currently works with 3,630 schools in 145 countries to develop and offer challenging educational programmes to over 1,121,000 students aged 3 to 19 years (http://www.ibo.org/general/who.cfm). This system not only gives high quality school education but also develops unique personal qualities which are defined as competencies of future leaders (Shneider M., 2005). The IB offers three programmes of international education from early childhood to pre-university age: The Primary Years Programme (the PYP) for students aged 3 to 12, the Middle Years Programme (the MYP) for students aged 11 to 16 and the Diploma Programme (the DP) for students aged 16 to 18. If at the end of the DP students pass external exams successfully they get high school diplomas that are recognized by 2800 world's leading universities.

Nowadays in Russia 18 schools are authorized as IB World Schools (http://www.ibsa.su/?partition=2). Education in the IB DP is substantially different from traditional national Russian educational system. Firstly, the IB DP provides students with the opportunity to choose their own educational trajectory while in the Russian national school system students do not have the choice of subjects. IB Diploma Programme students must choose one subject from each of five subject groups: languages, sciences, mathematics, individuals and societies, literature. These subjects can be taken either at higher level or at standard level. Some of the subjects offered by the IB Programme (Business\&Management, Psychology) can not be studied within the traditional national Russian school framework. Secondly, the IB DP includes one unique subject - "Theory of knowledge". This course develops critical thinking, gives students an opportunity to inquire into the nature of knowing and deepens their understanding of knowledge as a human construction. (http://www.ibo.org/diploma/index.cfm). Thirdly, students are involved in a variety of research projects in different subjects. Moreover, they have to choose the research question and plan their project themselves. One example of these research projects is the extended essay which is about 4000 words and asks students to engage in independent research through an in-depth study of a question relating to one of the DP subjects. Fourthly, 150 hours should be devoted to "Creativity, action, service" which involves students in a range of extra-curricular activities. This aspect of the programme enhances students' personal and interpersonal development through helping the society. Thus, the main aim of the IB DP is balanced personal development, forming critical and creative thinking skills and a positive attitude toward 
learning.

In Perm region an attempt was made to incorporate three IB programmes in the system of school education. For the purpose of our analysis we will describe two characteristics of this educational initiative: 1) funding model and 2) network character of the project. Firstly, this project is almost completely funded by the local government. Regional authorities allocate on average about $\$ 9000$ per one child in this programme while families pay about $\$ 1000$, which is about one tenth of the whole amount. Thus, regional authorities are responsible for financing the education while in other countries and even in other Russian regions such education is privately funded by students' families. If in our case this project had been funded by the families themselves it would not have been implemented, because it would have faced the following difficulties:

1) insufficient demand: families would not be ready to pay for this education because the minimal cost of education within this programme is about $\$ 10000$ per year.

2) longer period of launching the project: in order to be authorized by the IB to offer these programmes schools need substantial human and financial resources.

The second characteristic is what was called "the network character of the project" in the official documents. Here it means that the success of one school in implementing new educational standards and practices required by the IB will lead to the wide-spread expansion of acquired knowledge in the regional educational system and in its turn, will improve the work of teachers in other schools (Schleicher, 2011).

\section{Results}

Having analyzed official government documents on this educational initiative we can state that its primary aim is "to create organizational and pedagogical conditions for international educational programmes implementation in Perm region" which in its turn will lead to:

- "creating conditions for attracting highly-skilled specialists from other countries (there is shortage of such specialists in Perm region which lowers the pace of economic development and decreases its investment potential)

- the fact that school-leavers will get an internationally recognized diploma which gives them an opportunity to enter foreign universities

- high quality of education on sciences and humanities, better English-language skills as well as personal development which is a key feature of the IB programme" (Decree of the Perm Krai Government..., 2007).

Furthermore, it was expected that this project will "be a starting point for improving skills of a great number of teaching employees... by spreading the ideas and educational technologies of the IB in Perm region" (Decree of the Perm Krai Government..., 2007). It was decided that this project would be state-funded due to the following reasons: shorter period of school authorization and the fact that access to this program should be open not only for people aiming to work abroad but also for talented children in Perm region. This document describes the following points as possible risks 1) low demand due to high price of the service; 2 ) the fact that students can be overloaded due to the necessity to combine Russian national school programme and the IB programme; 3) outflow of trained human resources from this programme in the medium-term due to emotional, psychological and professional burnout. The following points were defined as indicators of successful performance 1) budget disbursement, 2) the number of authorized schools, 3) the number of students enrolled in the IB programme.

Within the period of three years three schools in Perm region were authorized by the IB and got the status of IB schools: one school provides The Primary Years Programme, the second - the Middle Years Programme and the third the Diploma Programme. In this paper we will analyze the DP only because two other programmes are combined with the Russian national curriculum and are free of charge for families, while only the DP puts special emphasis on getting an international diploma.

From our point of view, in order to identify and analyze benefits and risks of this project it might be useful to compare the opinions of key project beneficiaries. To achieve this aim the survey of three key beneficiary groups was conducted: students, graduates and teachers. The authors made an attempt to conduct a survey for families of the DP students but no questionnaires were filled out and returned.

\subsection{Students: survey results}

In 2012 - 2013 academic year 21 students were enrolled in the DP in Perm, the sample was continuous in this case. The 
survey results showed that $30 \%$ of students took independent decision to be educated in this programme, $60 \%$ made this decision together with their parents and in $10 \%$ cases this decision was taken by the parents.

Students gave diverse answers when asked about the reasons for choosing the DP. The most frequent answers were the following: "the experience of studying in English", "the possibility to improve English-language skills", "appealingness of the unusual educational system", "novelty of the curriculum", "preparation for further education abroad", "support in self-development".

Two thirds of the respondents are of the opinion that studies in the DP fully meet their expectations, the others consider that there is some gap between their expectations and the real studying process. When asked to describe this gap students noted rigid assessment system, difficulty in combining national and international curriculums, high level of formality in the educational process, lack of necessary infrastructure, provided in some IB schools abroad.

The most frequent answers about positive aspects of education in DP were the possibility to improve Englishlanguage skills (100\%) and learn new subjects which are not offered within the national educational curriculum (100\%). $80 \%$ of the respondents mentioned the fact that education is provided in small groups, $60 \%$ - state funding, $50 \%$ research projects and $45 \%$ - good preparation for further university studies.

When asked about the drawbacks of this program respondents gave the following answers: the necessity to combine national and international curriculum (85\%), dramatic increase in the study load (65\%).

The next question was about key differences between IB DP and Russian national curriculum. $50 \%$ of respondents mentioned the development of analytical thinking skills and skills to support arguments and judgments, 20\% named personal development. Some respondents mentioned more responsible attitude to the educational process, opportunity to choose necessary and interesting subjects.

\subsection{School-leavers: survey results}

In 20116 school-leavers received IB Diplomas in Perm region, in 2012 there were 14 of them. Out of these 20 people $50 \%$ get higher education in Perm, 30\% - in Moscow or St Petersburg, 20\% chose foreign universities in such countries as Germany, the UK, the USA.

15 respondents took part in our survey which is $75 \%$ of continuous sample; all of them were first or second year students in different universities at the time of our survey. The answers about the influence of the IB DP on the choice of the university were highly controversial: $50 \%$ of respondents think that the IB DP influenced their choice of the higher educational establishment to a great extent while the other $50 \%$ consider that there was no influence at all.

The vast majority of the respondents (80\%) are of the opinion that their experience of studying in the IB DP results in the successful university performance. They supported their opinion with the arguments about certain skills development (from the most frequent to the least frequent): critical thinking skills, skills to find relevant information, skills to plan and conduct scientific research, skills involved in the studying process. Some graduates expressed the opinion that their positive results at university depend on their knowledge of individual subjects studied in the IB DP.

The most frequent answers about positive aspects of education in the DP were possibility to choose different subjects (80\%), possibility to improve English-language skills (60\%), small groups of students (50\%), possibility to learn new subjects (50\%), conducting research projects (40\%), good preparation for university (50\%), state funding (40\%). Individual answers mentioned high motivation to study.

When asked about the drawbacks of this program, respondents gave the following answers: the most frequent was the necessity to combine national and international curriculum (70\%), dramatic increase in the study load (20\%), the lack of some subjects offered in the national curriculum (20\%).

We also asked the graduates to mention key differences between the IB DP and Russian national curriculum. The most frequent answers were development of thinking skills (50\%), development of skills to conduct scientific research $(50 \%)$, raising interest to the studying process (20\%), quality of education (20\%).

\subsection{Teachers: survey results}

There are 11 teachers in the IB Diploma Programme provided in Perm region, 9 of them (82\%) took part in our survey. Among the most frequent teachers' answers about the advantages of the DP were "teaching skills development" (78\%), "improvement of English-language skills" (78\%), "introduction to the international pedagogical experience" (78\%), "opportunity to become a part of international teaching community" (67\%). Some teachers also mentioned personal development, in particular such qualities as self-discipline and commitment. When asked about the disadvantages, the 
teachers mentioned a big amount of paperwork and reports (67\%), difficulties in delivering the curriculum and ambiguity of assessment criteria.

While answering the question "Are you ready to share your knowledge and skills, developed in this programme, with other teachers?", the opinions were divided equally. $50 \%$ of the DP teachers were ready to share, however, the others were reluctant to do so.

On the whole, since this programme was launched in 2009 in Perm region, the teaching team has become bigger, new specialists joined the group. Even more, English-language native speakers take part in delivering this programme: a history teacher and an English-language teacher.

\section{Discussion}

\subsection{Limitation of research}

The assessment of educational reforms or individual initiatives faces a number of difficulties and here we will name some limitations of our research. To begin with, all major effects and consequences of any educational project can be seen only in the long term. That is why attempts to estimate the project within the framework of 5 years will give limited results. The second difficulty is connected with the nature of the educational system which is a complex social and economic phenomenon which means that it would be irrelevant to analyze educational initiatives only from the economic or financial perspective (in this case - budget disbursement). Nevertheless, economic perspective should be taken into account as there is a well-developed theory of education as a public good which proves the need in government funding for educational system because future workforce productivity depends on the education quality (Hanushek et al., 2007; Heckman et al., 2003). Moreover, the issue of proportion in which the government and private sector (families, households) should finance education can be analyzed from the economic perspective as well. The private-public issue in education 1) does not have a universal answer and countries with high quality educational systems can have different approaches to it 2) is not static which means that approaches to this issue can vary even within the framework of one country 3) is not always acknowledged by economists and administrators in the sphere of education (Marginson, 2007) 4) a topical issue in Russia because it is central to the present-day restructuring process of education.

\subsection{Criteria for assessment}

Taking into account existing limitations every researcher has to describe their own criteria to assess educational reforms or rely on authoritative opinion. I. Froumin and P.Polyarush (2008) offer the following criteria to assess educational reforms (initiatives): increase in the quality of education, widening educational opportunities for everybody and a greater choice of educational innovations (Frumin et al., 2008). If we apply these criteria to the educational initiative analyzed in our paper we will have to describe this project as highly successful because it perfectly meets the first and the third criteria. As for the second criteria - widening educational opportunities for everybody - it can be partly applied as well, because there are these opportunities, however, access to them can be limited by the need for families to co-finance this educational initiative. However, these criteria do not allow us to elicit all important effects, that is why we will analyze risks and benefits for key beneficiary project groups.

\subsection{Risks and benefits for key beneficiary project groups}

Main beneficiaries of IB educational initiative in Perm region are the following:

In the private sector

1) students (and their families), school-leavers. One of the main advantages for this group is the fact that they get high quality international education which can result in the internationally recognized diploma of high school education and opportunity to enter high-profile universities abroad. In some cases university education can be shorter for students with IB diploma because they have already coved part of the subjects. Such qualities as personal development, critical thinking skills and ability to study which are stated in the official documents and described in the surveys can be regarded as the long-term results of the project. As for the risks, we can mention that all students get two diplomas simultaneously - Russian national diploma and international IB diploma.

2) teachers. The participation in this project gives them an opportunity to develop unique competences and 
advance their professional development. This can be obtained due to regular participation in local and international conferences and workshops, constant training in skills improvement (for example. Englishlanguage skills), taking advantage of granted access to advanced educational resources including text-books, exam papers, teaching materials. As for the risks for this group it can be investments in human capital which teachers have to make as well as high workload as a result of the need to combine work and constant training. In the public sector:

1) regional educational system in the face of schools and local Ministry of Education. Three schools where this initiative is based got massive investments in their infrastructure. In order to become an authorized IB school and offer one of the IB programmes these school had either to build or to improve their science laboratories, language centers, gyms, school halls, as well as purchase a great number of books, encyclopedias, reference books, access to on-line resources. However, there are some risks involved, for example, reputational risk because if this programme is not implemented successfully school reputation can be undermined both for the local government and wider local community.

2) local Ministry of Education with its primary aim to improve regional educational system. Apart from this primary aim we can name some side-effects such as advanced career development and improved professional status of the project leaders in case this unique educational initiative is successfully implemented as well as ability to control larger amounts of state finances. At the same time the following risks can be mentioned. Firstly, excess demand for this service form families and students in the short term. If the governments funds $90 \%$ of the service, the demand for it will naturally increase. On the one hand, it seems to be a good thing because the most capable students can be selected, however, under institutional conditions in Russia we can not be sure that this selection will be organized correctly. At the same time, if families had to self-finance education of their children in the IB programme, they would have fewer incentives to pay for the children who are not able to comply with the requirements or pass external exams successfully. Secondly, adverse selection for teachers should be mentioned here. It is a well-known situation when an employee gets training in one organization and then finds a better paid job elsewhere. Thirdly, it is stated in the official project documents that innovative educational approaches should be spread in the regional educational system. However, it requires additional efforts and finances otherwise it will never be realized.

\subsection{Unattained goals}

First of all, it is not clear (and it is difficult to analyze) whether the introduction of the IB programme increased investment potential of Perm region, attracted foreign highly-skilled specialists or contributed to the preparation of local professional managers as stated in the government reports (Public report..., 2011). In addition, "Human Recourses Center" was organized as a part if the IB initiative with the aim to implement IB methodology in the working practice of all teachers in the region who might be interested in it. However, its capacity is limited and the demand is low.

\section{Conclusions and recommendations}

This paper is an attempt to summarize first results of the government educational initiative launched in April 2007. The authors analyzed its positive and negative effects for key beneficiaries of the project. Based on the obtained results the following recommendations can be given. First of all, incentives should be found for selecting more motivated students (and their families) to be enrolled in the project. For example, personal letter of motivation must be an obligatory requirement for admission to this programme. This could increase project effectiveness because survey results show that students' choice of this programme can not be described as conscious or informed. Secondly, it is necessary to develop "the networking character of the project" described in the official documents and to improve performance of the "Human Recourses Center". For example, practicing DP teachers can be employed as teacher trainers to accelerate the widespread expansion of acquired knowledge in the regional educational system.

\section{References}

Decree of the Perm Krai Government "Introduction of Baccalaureate Programme in Perm Region as a part of the "New school Project" (2007) [Online] Available: http://www.iboperm.perm.ru/documents/provision/ (June 6, 2013)

Frumin, D., Polyarush, P. (2008). Partnership of State and Private Enterprises in Education: Lessons from International Experience. Journal of Educational Studies, 2, 73 - 107. 
Hanushek, E., Wossman, L. (2007) Education quality and economic growth. The World Bank.

Heckman, J., Krueger, A. (2003) Inequality in America: What role for human capital policy? MIT Press.

Kouzminov, Ya., Frumin, I., Zakharov, A. (2011). Russian school: an alternative to modernization from above. Journal of Educational Studies, 3, 5-53.

Marginson, S. (2007). The public/private divide in higher education: A global revision. Higher Education, 53, 307-333.

Public report of Perm Krai Ministry of Education "Educational system development if Perm region in 2010 - 2011 academic year" [Online] Available: http://www.iro.perm.ru/ (June 6, 2013)

Salmi, D., Frumin, I. (2013). Excellence initiatives to establish world-class universities: Evaluation of recent experiences. Journal of Educational Studies, 1, 25-68.

Schleicher, A., (2011), Building a high-quality teaching profession: Lessons from around the world, OECD Publishing. [Online] Available http://dx.doi.org/10.1787/9789264113046en (June 6, 2013)

Shneyder, M. (2005). The Assessment of Education Quality in the Schools of International Bacchalaureate. Journal of Educational Studies, 1, 2-28.

The long-term program "The development of educational system in Perm region in 2013 - 2017". [Online] Available: http://zsperm.ru/s1/performance_reviews/analytical_materials/pr_12_24012013.pdf (June 6, 2013)

www.ibo.org/general/who.cfm

http://www.ibsa.su/?partition=2 